\title{
Storage and Timed Release of Acetaminophen from Porous Carbonaceous Materials
}

\author{
Sarah E. McCary, Thomas R. Rybolt ${ }^{*}$ \\ Department of Chemistry, University of Tennessee at Chattanooga, Chattanooga, USA \\ Email: Tom-Rybolt@utc.edu
}

Received February 26, 2013; revised March 26, 2013; accepted April 28, 2013

Copyright (C) 2013 Sarah E. McCary, Thomas R. Rybolt. This is an open access article distributed under the Creative Commons Attribution License, which permits unrestricted use, distribution, and reproduction in any medium, provided the original work is properly cited.

\begin{abstract}
Six carbon powders with varied surface areas and porosities were used to store and release acetaminophen (ACT). A 10 $\mathrm{mg} / \mathrm{mL}$ solution of acetaminophen in phosphate buffer solution $(\mathrm{pH}=7.0)$ at $25^{\circ} \mathrm{C}$ with exposure to carbon powder for 72 hours was used to drive the maximum loading of acetaminophen into the powders. Carboxen 1012 (BET surface area of $1500 \mathrm{~m}^{2} / \mathrm{g}$ ) powder exhibited the greatest maximum adsorption of ACT (up to $62 \%$ by mass). The maximum ACT adsorption was correlated with surface area and porosity. The most effective carbon powders for binding ACT were ones containing high mesopore volumes. Loaded carbon powder was separated from the ACT solution and then phosphate buffer solution $(\mathrm{pH}=7.0)$ was combined with the loaded carbon powder and ACT absorbance readings at $243 \mathrm{~nm}$ were taken over time. The various carbon powders were able to release a portion of the ACT that they originally adsorbed. The Carboxen 1012 powder displayed the greatest ACT release with a rapid initial release followed by a steady but slightly declining release over a time period of 2 to 11 weeks. The results were supportive of mesoporous carbons such as Carboxen 1012 being suitable for drug loading and release.
\end{abstract}

Keywords: Carbon Powders; Drug Release; Adsorption of Acetaminophen; Mesoporosity; Storage of Acetaminophen

\section{Introduction}

There is interest in using mesoporous media (pores ranging in volume size from 2 to $50 \mathrm{~nm}$ ) as drug delivery systems. Researchers have tried loading various drugs on to mesoporous material and controlling the release rate of these drugs. This prior work has been done by using both silica and carbon mesoporous materials, modified mesoporous materials, and also carbon nanoparticles. Carbon nanotubes, for example, are of interest because of their small size, efficient drug delivery, low toxicity, and nonimmunogenic characteristics [1]. Kam et al. studied in vitro how single-walled carbon nanotubes (SWNTs) could not only transport a drug but destroy cancer cells [2,3].

Animal trials have been performed using BioSilicon (a nanostructured porous silicon) for carrying and releasing the radioactive isotope Phosphorus-32 [4]. Clinical trials have been undertaken to investigate this short range radiotherapy approach for liver cancer treatment. Horcajada et al. examined the in vitro adsorption and control-release of ibuprofen (IBU) on MCM-41 (a porous silicate with pore sizes in the range of 3.6 to $2.5 \mathrm{~nm}$ ) [5].

\footnotetext{
${ }^{*}$ Corresponding author.
}

A decrease in pore size coincided with a decrease in the amount drug adsorbed (from $34 \%$ to $11 \%$ for pores of 3.6 $\mathrm{nm}$ to $2.5 \mathrm{~nm}$, respectively), and also in the rate of drug release $(24 \mathrm{mg} / \mathrm{hr}$ to $5 \mathrm{mg} / \mathrm{hr}$ for pores of $3.6 \mathrm{~nm}$ to 2.5 $\mathrm{nm}$, respectively). Some mesoporous silica materials can exhibit sustained-release properties, but their drug storage capacity can sometimes be relatively low [6]. A two-part drug-delivery system involving synthesized hollow mesoporous silica (HMS) spheres (a spherical cubic mesoporous aluminosilicate (Si-Al-MCM-41)) has been developed [7]. The HMS was nanoscaled spheres with pore channels connecting the outside surface to the inner hollow core. Drug release was doubly controlled by diffusion from the mesoporous silica and coated polyelectrolyte multilayers that can be affected by $\mathrm{pH}$ and ionic strength.

Due to carbon powder's lack of surface charge and hydrophobic nature, porous carbon could offer advantages such as loading and releasing proteins and remaining structurally stable under aqueous conditions. Various experiments have been performed utilizing carbon powders as drug delivery devices. Hagiwara et al. performed animal trails and clinical trials on activated carbon pow- 
ders loaded with anticancer drugs (mitomycin C or peplomycin) [8]. Activated carbon powders were attracted to lymph nodes and tumor surfaces near the injection site. The results showed that the carbon particles remained for a period of time at the site of application and released drug slowly.

Animal experiments showed that the therapeutic index (the lethal dose divided by the therapeutic dose) was three-fold higher for the loaded carbon powder than the unadsorbed mitomycin $\mathrm{C}$ in an aqueous solution. Clinical trials were performed on 81 patients with malignant pleural effusion (abnormal amount of fluid collecting in the pleural cavity, surrounding the lungs) and 51 out of 81 patients responded well. For chemotherapy against lymphatic metastasis, peplomycin was loaded onto carbon powder. In animal experiments, this loaded device was injected into the gastric wall of dogs. The trials showed that a high level of peplomycin was distributed to regional lymph nodes for a long time. The therapeutic efficacy of the loaded carbon powder on the lymphatic metastasis was greater than the peplomycin in an aqueous solution. Clinical trials were performed on patients with esophageal cancer, and 5 out of the 7 patients were able to extend their life by 9.4 months.

Hagiwara continued his work using activated carbon as a drug delivery device and a new therapeutic effective dosage of an anti-cancer drug bound to activated carbon was formulated against early gastric cancer [9]. The activated carbon particles used had a nitrogen BET (Brunauer, Emmett, and Teller) surface area of $1500 \mathrm{~m}^{2} / \mathrm{g}$ and a diameter of $20 \mathrm{~nm}$. The activated carbon powder loaded $329 \mathrm{~g}$ peplomycin/mg carbon powder and $270 \mathrm{~g}$ methotrexate $/ \mathrm{mg}$ carbon powder. In clinical trials, an anticancer drug loaded onto carbon powder was injected (250 - $250 \mathrm{mg}$ methotrexate per person or $40-100 \mathrm{mg}$ peplomycin per person) into the primary lesions. The results revealed that out of the 12 patients 8 patients showed no cancer after 12 to 64 months, 3 patients showed no cancer after 27 to 98 months, and 1 patient had to the treatment again after 26 months and was cancer free for 32 months.

Lu et al. investigated the adsorption and sustained-release of nifedipine (an anticancer drug) in spherical activated carbon (SAC) [10]. Their results showed that the SAC with high specific surface area and significant amounts of mesopores adsorbed the greatest amount, and provided the best sustained-release of nifedipine. The maximum adsorption capacity was $19.5 \mathrm{mg}$ nifedipine/g SAC, and the total release was $19.2 \%$.

Tae-Wan Kim et al. [11] used mesoporous carbon nanoparticle $(\mathrm{MCN})$ as a transmembrane delivery device for Fura-2 (a fluorescence dye that is a membrane impermeable chemical agent). The MCN material had an average particle size of $150 \mathrm{~nm}$, a BET surface area of
$2034 \mathrm{~m}^{2} / \mathrm{g}$, a total pore volume of $1.2 \mathrm{~cm}^{3} / \mathrm{g}$, and an average pore diameter of $2.4 \mathrm{~nm}$. Using cervical cancer cells, the results show that the inhibitory concentration of $\mathrm{MCN}$ was found to be greater than $50 \mathrm{~g} / \mathrm{mL}$ per million cells indicating that $\mathrm{MCN}$ is fairly biocompatible. Also, MCN material served as a transmembrane carrier for delivering Fura-2 inside cervical cancer cells.

Shohji Matsumoto et al. performed drug delivery experiments using activated carbon to adsorb and release aclarubicin [12]. The activated carbon adsorbed $207 \mathrm{~g}$ aclarubicin/mg carbon powder, and $43 \%$ of the aclarubicin was released from the activated carbon. Other research on activated carbon adsorbing and releasing acularubicin was performed by Chilhiro Yoneyama et al. to develop a better chemotherapy treatment [13].

Qiulian $\mathrm{Qu}$ et al. performed adsorption and sustainedrelease of mitomycin $\mathrm{C}$ (MMC) on the activated carbon nano-particles (ACNP) and activated carbon micro-particles (ACMP) [14]. The ACNP had a $132 \mathrm{mg} / \mathrm{g}$ adsorption capacity and the ACMP had a $118 \mathrm{mg} / \mathrm{g}$ adsorption capacity. A slow release of MMC adsorbed was observed after each time the supernatant was replaced with water. Further research was performed to calculate a new dosage of activated carbon nanoparticles adsorbing mitomycin C (MMC-ACNP), and its beneficial effects for lymphatic targeting in preventing metastasis and recurrence of gastric cancer [15]. Experimenting on mice with transplanted human gastric cancer showed that the $\mathrm{LD}_{50}$ (median lethal dose) of MMC-ACNP (46.80 mg/kg) was higher than the MMC aqueous solution value (9.33 $\mathrm{mg} / \mathrm{kg}$ ). The toxicity of MMC-ACNP was less than the toxicity of the MMC in aqueous solution. MMC-ACNP was superior in controlling tumor growth and the anticancer drug (MMC) was aided by the MMC-ACNP entering the nuclei of tumor cells.

Using rabbits, Hoshino et al. preformed controlledrelease experiments with activated charcoal carrying aminophylline [16]. In order for the drug to diffuse into blood capillaries via the rectal mucosa, activated charcoal was used in the form of an enema. The activated carbon vehicle was able to keep a constant plasma level of aminophylline for over 6 hours. The mean residence time of aminophylline from activated carbon was enhanced by 1.7-fold in comparison with aminophylline in solution.

Measoporous carbons have found further applications in gas separation, adsorption of small gas molecules, catalysis, energy storage and capacitors, as well as drug delivery devices $[12,13,17,18]$. Ajayan Vinu et al. discussed the progress of research in development of mesoporous media (silica and carbon) adsorbing biomaterials and the need for the development of better designed mesoporous media [17]. Studies have been performed on the adsorption behavior of amino acids, vitamins, proteins, 
and enzymes. Research has also been done with activated carbon combined with other substances to help better control drug release and to control where the device could go in the body. Controlling the release of chemicals could by aided by porous carbonaceous materials. One goal is to develop devices that avoid the problem of initially releasing a drug above the therapeutic concentration threshold, and then decreasing until the drug release falls below the therapeutic range.

The focus of our project is to exam the loading of acetaminophen onto various activated carbons and its subsequent release into a phosphate buffer solution at a temperature of $37^{\circ} \mathrm{C}$ and a $\mathrm{pH}$ of 7.0. In general, activated carbon is known to have a high porous surface area, which makes the compound an effective adsorbent. Physical adsorption of activated carbon involves nonspecific attraction or binding due to weak van der Waals forces. We wish to examine the amount of drug that can be stored for a series of carbon powders having a range of porosity profiles and surface areas, and compare the amount loaded to these surface area and porosity profiles. Further we wish to examine the subsequent release of drug from these various carbons and how the release profile can be varied by carbon porosity or loading conditions. By studying molecule adsorption and release from various carbons, we hope to better predict carbon characteristics that optimize these properties.

\section{Experimental Details}

\subsection{Preliminary}

4-hydroxyacetanalide, CAS number [103-90-2], also referred to as acetaminophen or paracetamol, is an overthe-counter analgesic and antipyretic. Acetaminophen (ACT) has a molecular formula of $\mathrm{C}_{8} \mathrm{H}_{9} \mathrm{NO}_{2}$ with a molecular weight of $151.2 \mathrm{~g} / \mathrm{mol}$. ACT consists of an aromatic benzene ring, substituted by an amide group (acetamide) and a hydroxyl group in the para position. Acetaminophen has an aromatic ring, is slightly polar, and is well adsorbed on activated carbon. ACT is not of specific interest as a time released therapeutic agent; but it represents a suitable small drug molecule for this study. The solubility of acetaminophen is $10 \mathrm{mg} / \mathrm{mL}$ at $25^{\circ} \mathrm{C}$ [19]. When activated carbon is added to an ACT solution, the ACT acts as an adsorbate and is attracted to the nonpolar carbon powder preferentially to an aqueous solution due to van der Waals forces.

Prior research studies have generally focused on one specific carbon powder at a time while studying the loading and releasing of specific drugs in different environments. However, this research is focused on an investtigation of a variety of activated carbons, containing different surface areas and pore sizes. The ability of these various carbon powders to retain and subsequently re- lease ACT were observed. The procedure consisted of loading the carbon powders in a concentrated solution of ACT, isolating the drug loaded carbon powders, and then releasing the ACT loaded on these carbon powders in a phosphate buffer solution at a $\mathrm{pH}$ of 7.0 and temperature of $37^{\circ} \mathrm{C}$.

Experiments were performed on the carbon powders: Carboxen 1000 (C-1000), Carboxen 1003 (C-1003), Carboxen 1012 (C-1012), Carboxen 1018 (C-1018), Carbopack B (CB), and Carbosieve S-III (CS) were supplied by Supelco and Decolorizing Carbon (DC) from Fisher Scientific. Concentrated potassium phosphate monobasic-sodium hydroxide buffer (Fisher) was diluted to make the final phosphate buffer solution (PBS) at $\mathrm{pH}=$ $7.0+/-0.02$. A direct-QTM Millipore filter system was utilized for the deionized water used for all dilutions, solutions, and rinsings.

All experiments followed the same general procedures for the loading, separating, and releasing. For loading acetaminophen (Aldrich) onto carbon powders, a stock solution was prepared by dissolving acetaminophen in $100 \mathrm{~mL}$ of the phosphate buffer solution. The activated carbon powders $(0.1 \mathrm{~g})$ were then mixed with $10 \mathrm{~mL}$ of this ACT solution in test tubes $(13 \times 100 \mathrm{~mm})$. Then the capped test tubes were placed in a shaker (New Brunswick Scientific I2400 Incubator) at a temperature of $25^{\circ} \mathrm{C}$ and shaken at $200 \mathrm{rpm}$. For separating, the loaded carbon powder had to be removed by filtration from the ACT solution and placed in a buffer solution. For all releasing experiments, the loaded carbon powders were placed in the $\mathrm{pH}=7.0$ phosphate buffer with the temperature maintained in a bath at $37^{\circ} \mathrm{C}$. Periodic absorbance readings were taken to determine how much ACT had been released into the solution.

For determining the amount of ACT loaded and released, a dual beam UV-Visible spectrometer (Cary 100 Bio) was utilized with sample and reference placed in quartz cuvettes. The maximum absorption occurred at a wavelength of $243 \mathrm{~nm}$ as had been observed in previous research [20]. A $1.0 \mathrm{~nm}$ slit width was used in all the absorbance readings. Quartz cuvettes were rinsed three times with deionized water between readings. The reference cuvette contained phosphate buffer solution. Three absorbance readings were taken and averaged for every sample. To detect variations and abnormalities that might result from heating, shaking, or interference of carbon, a blank control solution containing only solution and no carbon powder was used for every experiment and an additional control solution with carbon and no ACT was used to check for possible powder interference.

Several sets of six or seven dilutions ranging from $0.0020 \mathrm{mg} / \mathrm{ml}$ to $0.030 \mathrm{mg} / \mathrm{ml}$ were made from an ACT solution. During the course of our work, periodic Beer's Law experiments $(243 \mathrm{~nm})$ were performed to determine 
if the absorptivity values remained constant overtime. Beer's law based absorbances, $\mathrm{A}=\varepsilon b \mathrm{~b}$, where $\varepsilon$ is the absorptivity constant, $\mathrm{b}$ is the path length of the light passing through the cuvette containing the sample, and $\mathrm{C}$ is the concentration of the sample were then used to calculate the concentration of ACT solutions. The concentration is normally expressed in $\mathrm{mol} / \mathrm{L}$ but in this work it was defined in $\mathrm{mg} / \mathrm{mL}$. To determine the amount of drug adsorbed, the solution concentration was measured before and after exposure to the adsorbent.

To understand the correspondence between the concentration of ACT and the amount loaded on the activated carbon, two different loading solution concentrations were observed. In an initial experiment, $0.1 \mathrm{~g}$ of three different carbon powders, (Decolorizing Carbon, Carbopack B, and Carboxen 1000) were placed either into $10 \mathrm{~mL}$ of one of two loading solutions: $1.0 \mathrm{mg} / \mathrm{mL}$ or in a $10.0 \mathrm{mg} / \mathrm{mL}$ ACT in phosphate buffer solution.

An initial loading time experiment was performed using the Decolorizing Carbon to determine the role of time in loading ACT onto a carbon powder. Approximately, 0.1 grams of DC was measured into a test tube, mixed with $10 \mathrm{~mL}$ of stock solution (approximately $10 \mathrm{mg} / \mathrm{mL}$ of ACT solution) and shaken for a period of time. The total amount of ACT in solution $100 \mathrm{mg}$ per $0.1 \mathrm{~g}$ of carbon is equivalent to $1000 \mathrm{mg} / \mathrm{g}$ ( $\mathrm{mg}$ of ACT per $\mathrm{g}$ of carbon) well beyond what was ever adsorbed. Absorbance readings were taken at 20, 42, 65, and 123 hours. After 20 hours the ACT adsorption was $99 \mathrm{mg}$ per $\mathrm{g}$ of carbon and after 42 hours the adsorption was $217 \mathrm{mg} / \mathrm{g}$. No further adsorption occurred after 65 or 123 hours. In subsequent loading experiments, 72 hours was used as the total equilibration loading time.

Several different types of powder separation procedures were examined, but the approach that worked best was using the Millipore Sterifil Asceptic System and Sterifil $47 \mathrm{~mm}$ Filter Holder (a vacuum filtration system). With this approach carbon powder was not lost and the carbon was effectively removed from the ACT solution. Four different filters (Glass Fiber filter, Polycarbonate Membrane, General Membrane filter, Millipore Durapore PVDF Membrane filter) were tried. The Durapore PVDF Membrane filter was the best filter because the carbon powder and ACT solution were separated, no ACT solution was retained on the filter, no filter fibers were observed in the solution after filtration, and no carbon powder was lost. This filter was made of polyvinylidene fluoride (PVDF). In order to dry the filter and carbon powder, the filter and the carbon powder remained on the vacuum-filter system for 15 minutes and then the filter removed carbon powder were placed in a drying oven at $100^{\circ} \mathrm{C}$ for 15 minutes. The filter was not damaged under these drying conditions.

To determine the amount of ACT loaded onto carbon powder and the amount of ACT released from the carbon powder, three procedures were performed: the loading of ACT onto the carbon powder, the separating of carbon powder from the loading solution, and the releasing of ACT from the carbon powder. A total of six carbon powders were used for these three procedures: Carbopack B, Carboxen 1000, Carbosieve S-III, Carboxen 1003, Carboxen 1018, and Carboxen 1012. In addition to these six samples, two controls were used each time. One control had only ACT in buffer solution $(10 \mathrm{mg} / \mathrm{mL})$ and a second had powder in buffer and no ACT. A control for the loading experiments was $10 \mathrm{~mL}$ of stock solution (approximately $10 \mathrm{mg} / \mathrm{mL}$ ACT) undergoing loading conditions but without powder.

\subsection{Loading Experiment}

The loading experiment determined the amount of ACT loaded onto the six different carbon powders. For the loading procedure, $100 \mathrm{~mL}$ of $10 \mathrm{mg} / \mathrm{mL}$ ACT stock solution was prepared using the $\mathrm{pH}=7.0 \mathrm{PBS}$. Heating to $50^{\circ} \mathrm{C}$ was used to facilitate dissolving the ACT.

In a subsequently closed test tube, $0.1 \mathrm{~g}$ of carbon powder and $10 \mathrm{~mL}$ of stock solution were mixed and then placed on the shaker at $200 \mathrm{RMP}$ and $25^{\circ} \mathrm{C}$ for 72 hours. Afterwards, the test tube was stirred with a touch mixer and then centrifuged for initial powder separation prior to collecting a sample with micropipet. Since the ACT solution for loading has a high concentration, the solution was typically diluted by a factor of $500(0.020$ $\mu \mathrm{L}$ sample of solution was diluted to $10 \mathrm{~mL}$ in volumetric flask) and then the dilution was stirred with a touch mixer. Absorbance values were taken and converted, using Beer's law in the form of Equation (2), to the concentration of ACT loaded onto the carbon powder.

\subsection{Separation Experiment}

Before ACT could be released from the six different carbon powders, the carbon powders were separated from the loading solution. For the separation procedure, the initial mass of the filter was weighed and placed on the vacuum-filter system. The carbon powder solution was poured onto the filter by setting the test tube on top of the filter, and once all the liquid was filtered, the test tube was removed from the filter. The test tube was rinsed with buffer solution to remove any residual carbon powder left in the test tube. The vacuum-filter system was left to run for 15 minutes for initial drying, then the powder removed from the filter followed by drying in an oven at $100^{\circ} \mathrm{C}$ for 15 minutes. An absorbance reading was taken of the solution in the collecting container (rinsed solution and ACT solution obtained during filtration). After the drying procedure, the final mass of the filter and loaded carbon powder were measured. 


\subsection{Releasing Experiment}

The releasing experiment determined the amount of ACT released from the six different carbon powders. For the releasing procedure, the loaded carbon powder was placed in $250 \mathrm{~mL}$ of buffer solution at $37^{\circ} \mathrm{C}$ and absorbance measurements were taken over a period of time. Before taking absorbance readings, the flask was stirred by a touch mixer. After the carbon powder resettled to the bottom, a volumetric sample of the solution was taken to be analyzed. This cumulative release continued until the loaded carbon powder stopped releasing ACT.

After this initial period of release was completed, then another cumulative release was begun by pouring out the solution and leaving behind the carbon powder in the flask. To prevent the loss of carbon powder, the Millipore vacuum-filtration system was used. All the carbon powder was placed back into the flask. Then a fresh 250 $\mathrm{mL}$ buffer solution was poured into the flask with the carbon powder and placed in the bath at $37^{\circ} \mathrm{C}$, again. These subsequent release procedures were repeated, as necessary, over a period of many weeks until the carbon powder did not release any more ACT.

\section{Analysis and Results}

\subsection{Preliminary}

All ACT absorbance values were obtained at $243 \mathrm{~nm}$ using a slit width of $1.0 \mathrm{~nm}$ and limited to concentrations within the linear region of the Beer's Law plot. Calibration curves from different times at the same wavelength gave an average absorptivity constant of $=9565 \mathrm{~cm}^{-1} \cdot \mathrm{mol}^{-1} \cdot \mathrm{L}$ or $=63.27 \mathrm{ml} \cdot \mathrm{cm}^{-1} \cdot \mathrm{mol}^{-1}$ (standard deviation percent error was $1.7 \%$ ). Quartz cuvettes with a $1.00 \mathrm{~cm}$ path length were used. The final Beer's law equation was used was

$$
\mathrm{A}=\left(9565 \mathrm{~cm}^{-1} \cdot \mathrm{mol}^{-1} \cdot \mathrm{L}\right)(1.00 \mathrm{~cm}) \mathrm{C}\left(\mathrm{mol} \cdot \mathrm{L}^{-1}\right)
$$

or more commonly used was the working equation of

$$
\mathrm{A}=\left(63.27 \mathrm{ml} \cdot \mathrm{cm}^{-1} \cdot \mathrm{mg}^{-1}\right)(1.00 \mathrm{~cm}) \mathrm{C}\left(\mathrm{mg} \cdot \mathrm{mL}^{-1}\right)(2)
$$
with the concentration expressed as $\mathrm{mg}$ ACT per $\mathrm{mL}$ of buffer at $\mathrm{pH}=7.0$.

Controls showed no carbon powder interference with the absorbance values, and the absorbance measured ACT concentrations varied less than $1 \%$ from volumetrically measured concentrations.

The final absorbance values $\left(\mathrm{A}_{\mathrm{f}}\right)$ of the controls and samples were obtained and converted into final concentration values, $\mathrm{Cf}$. The absorptivity constant $(\varepsilon)$ calculated in the Beer's law experiment was used to calculate the final absorbance measured concentration values based on

$$
\mathrm{C}=\mathrm{AF} / \varepsilon
$$

where $\mathrm{F}$ is the dilution factor. Three absorbance readings were averaged for each sample.

In initial experiments carbon exposure to a $1.0 \mathrm{mg} / \mathrm{mL}$ ACT in PBS solution for 18 hours and to a $10.0 \mathrm{mg} / \mathrm{mL}$ solution for 42 hours resulted in ( $\mathrm{mg} \mathrm{ACT} / \mathrm{g}$ carbon) of: $(38,91,95)$ and $(131,449,476)$ for CB, DC, and C-1000 powders, respectively. Not surprisingly the adsorption could be enhanced up to a point by longer exposure times and higher concentrations.

Once the final concentrations $\left(\mathrm{C}_{\mathrm{f}}\right)$ of the ACT solutions were calculated for from the absorbance readings, the amount of ACT loaded onto the carbon powders could be calculated. First the mass of ACT remaining in solution $\left(\mathrm{m}_{\mathrm{AS}}\right)$ was calculated, second the mass of ACT loaded on the carbon powder $\left(\mathrm{m}_{\mathrm{AL}}\right)$ was calculated, and third the amount of loaded ACT per gram of carbon powder $\left(\mathrm{N}_{\mathrm{AL}}\right)$ was calculated as shown below.

$$
\begin{gathered}
\mathrm{m}_{\mathrm{AS}}=\mathrm{C}_{\mathrm{f}} \mathrm{V}_{\mathrm{L}} \\
\mathrm{m}_{\mathrm{AL}}=\left(\mathrm{m}_{\mathrm{S}}-\mathrm{m}_{\mathrm{AS}}\right) \\
\mathrm{N}_{\mathrm{AL}}=\mathrm{m}_{\mathrm{AL}} / \mathrm{m}_{\mathrm{C}}
\end{gathered}
$$

where $\mathrm{V}_{\mathrm{L}}$ is the volume of the loading solution, $\mathrm{m}_{\mathrm{S}}$ is the mass of ACT in stock, and $m_{C}$ is the mass of carbon powder. A solution $10 \mathrm{mg} / \mathrm{mL}$ of ACT was used as the concentration for all subsequent loading experiments.

\subsection{Loading}

The analysis of ACT adsorbed on various carbon powders was performed in order to determine the amount of ACT that can be loaded onto carbon powders with different surface areas and pore sizes. Table 1 gives the results of these loading experiments. For comparison to powder characteristics, Table 2 gives the amount of ACT adsorbed for each carbon powder from above compared to its nitrogen BET surface area and pore volumes of micro, meso, and macro pores. Micropores possess a diameter less than $2 \mathrm{~nm}$, mesopore are characterized by a diameter range between 2 to $50 \mathrm{~nm}$, and macropores have diameter greater than $50 \mathrm{~nm}$. These area and porosity parameters were available from Supelco, and the BET surface area of Carbopack B was determined (Micromeritics).

As shown in Table 2, Carboxen 1012 was the carbon powder that adsorbed the most ACT. This carbon powder had the largest BET surface area and the highest mesopore volume. Carboxen 1003 rather than Carboxen 1000, was the next carbon powder to adsorb the most ACT. Carboxen 1003 has a smaller BET surface area than Carboxen 1000 however it also has a larger mesopore volume. Having a smaller BET surface area and only micropores, Carboxen 1018 was the fourth carbon powder to adsorb the most ACT. Carbopack B having no significant porosity and the lowest BET surface area, it 
Table 1. Loading experiments: based on absorbance with loading solution of $10.0 \mathrm{~mL}$.

\begin{tabular}{|c|c|c|c|c|c|c|c|}
\hline Carbon Type & Carbon (g) & Abs & Dilution factor & $\mathrm{C}_{\mathrm{f}}(\mathrm{mg} / \mathrm{mL})$ & Final Mass (mg) & Loaded ACT (mg) & $\mathrm{ACT} /$ Carbon $(\mathrm{mg} / \mathrm{g})$ \\
\hline $\mathrm{CB}$ & 0.1005 & 1.2364 & 500 & 9.771 & 97.7 & 2.3 & 23 \\
\hline C-1018 & 0.1000 & 1.0054 & 500 & 7.945 & 79.5 & 20.5 & 205 \\
\hline $\mathrm{CS}$ & 0.9970 & 1.2651 & 500 & 9.998 & 100.0 & 0.0 & 0.0 \\
\hline C-1003 & 0.1004 & 0.7491 & 500 & 5.920 & 59.2 & 40.8 & 406 \\
\hline C-1000 & 0.1011 & 0.7977 & 500 & 6.304 & 63.0 & 37.0 & 366 \\
\hline C-1012 & 0.1006 & 0.4731 & 500 & 3.739 & 37.4 & 62.6 & 622 \\
\hline
\end{tabular}

Table 2. Comparing loading results for $10.0 \mathrm{~mL} \mathrm{of} 10.0 \mathrm{mg} / \mathrm{mL}$ ACT solution and $0.1 \mathrm{~g}$ of carbon with surface area and pore volume for various powders. Loading time of 72 hours.

\begin{tabular}{cccccc}
\hline \multirow{2}{*}{$\begin{array}{c}\text { Carbon } \\
\text { Type }\end{array}$} & $\begin{array}{c}\text { BET Surface } \\
\text { Area }\left(\mathrm{m}^{2} / \mathrm{g}\right)\end{array}$ & Micro & Meso & Macro & Dolume $\left(\mathrm{cm}^{3} / \mathrm{g}\right)$ \\
\cline { 3 - 5 } Carbon $(\mathrm{mg} / \mathrm{g})$ & \\
\cline { 3 - 5 } CB & 90 & 0 & $(2-50 \mathrm{~nm})$ & $(>50 \mathrm{~nm})$ & 23 \\
C-1018 & 675 & 0.35 & 0 & 0 & 205 \\
CS & 975 & 0.35 & 0.04 & 0 & 0 \\
C-1003 & 1000 & 0.38 & 0.26 & 0.28 & 406 \\
C-1000 & 1200 & 0.44 & 0.16 & 0.25 & 366 \\
C-1012 & 1500 & 0 & 0.66 & 0 & 622 \\
\hline
\end{tabular}

adsorbed the fifth least amount of ACT.

Carbsieve S-III had a relatively high nitrogen BET surface area, but adsorbed no acetaminophen. Carbosieve $\mathrm{S}-\mathrm{III}$ is known to have uniformed small pores, and these pore diameters are too small to accommodate the ACT molecule [21]. Carbosieve S-III pores in prior work were found to be mostly $0.55 \mathrm{~nm}$ in diameter, determined from a nitrogen pore volume distribution analysis [21].

A multiple linear regression was used to determine a general relationship between the adsorption of ACT onto the carbon powders and the various physical properties of the carbon powders (BET surface area and volume of micropores, mesopores, and macropores). The first multiple linear regression equation was calculated to compare the amount of ACT (mg) per gram of carbon to the BET surface area and the different amounts of each sized pore (based on data in Table 2). The result was

$$
\begin{aligned}
\mathrm{N}_{\mathrm{AL}}= & -0.33472 \mathrm{SA}_{\mathrm{BET}}+866.78 \mathrm{~V}_{\text {Micro }}+1601.4 \mathrm{~V}_{\text {Meso }} \\
& +19.30 \mathrm{~V}_{\text {Macro }}+53.55
\end{aligned}
$$

and $\mathrm{r}^{2}=0.918$ where $\mathrm{N}_{\mathrm{AL}}$ represents the amount of ACT (mg) loaded per gram of carbon, $\mathrm{SA}_{\mathrm{BET}}$ is the nitrogen BET surface area, $V_{\text {Micro }}$ is the pore volume due to micropores, $\mathrm{V}_{\text {Meso }}$ is the pore volume due to mesopores, and $\mathrm{V}_{\text {Macro }}$ is the pore volume of macropores. The result shows that ACT adsorption depends primarily on mesopores and to a smaller a degree on micropores, but little on macropores. The amount of mesopores correlates with the greatest ACT adsorption. The lowest coefficient of the three pore volumes in the multiple linear regression equation is associated with the macropores and surface area has a negative correlation.

Since Carbosieve S-III's micropores had a diameter too small to adsorb ACT, another multiple linear regression equation was calculated with same data as before, except Carboseive S-III's micropores volume was changed to zero. $\mathrm{V}_{\text {Micro }}(\mathrm{CS})=0$. The result with $\mathrm{V}_{\text {Micro }}(\mathrm{CS})=$ 0 and other data from Table 2 was

$$
\begin{aligned}
\mathrm{N}_{\mathrm{AL}}= & -0.059053 \mathrm{SA}_{\mathrm{BET}}+650.98 \mathrm{~V}_{\text {Micro }}+1040.7 \mathrm{~V}_{\text {Meso }} \\
& -215.02 \mathrm{~V}_{\text {Macro }}+21.63
\end{aligned}
$$

with $\mathrm{r}^{2}=0.998$. This second multiple linear regression equation again shows that mesopores primarily affect the amount of ACT adsorbed onto the carbon powder. Micropores also are shown as contributing to the adsorption of ACT, but the BET areas and the macropores are shown to both have negative correlations.

Since ACT adsorption does not seem to depend significantly on the SABET term for either of the previous regression equations, another multiple linear regression equation was calculated with the same data as the prior analysis but with the BET surface area parameter re 
moved and again $\mathrm{V}_{\text {Micro }}(\mathrm{CS})=0$. The result was

$$
\begin{aligned}
\mathrm{N}_{\mathrm{AL}}= & 610.43 \mathrm{~V}_{\text {Micro }}+948.92 \mathrm{~V}_{\text {Meso }} \\
& -215.21 \mathrm{~V}_{\text {Macro }}-6.86
\end{aligned}
$$

and $\mathrm{r}^{2}=0.993$. This third multiple linear regression equation again shows that mesopores contribute more to the adsorption of ACT than micropores.

Finally a fourth multiple linear regression was carried out (again using $\mathrm{V}_{\text {Micro }}=0$ for Carbosieve S-III) with only micropore and mesopore volumes as variables. The resulting equation was

$$
\mathrm{N}_{\mathrm{AL}}=500.18 \mathrm{~V}_{\text {Micro }}+922.76 \mathrm{~V}_{\text {Meso }}+0.52
$$

and $\mathrm{r}^{2}=0.988$ where again the microporosity contributes but the mesoporosity dominates.

\subsection{Separation}

In order to determine the amount of ACT loaded onto the carbon powders after the separation procedure, two methods were used to calculate the amount of ACT per carbon powder. After the loaded carbon powder was rinsed, the data obtained through weighing various parts of the separation experiment were used to calculate the ACT per carbon powder, $\mathrm{N}_{\mathrm{AL}}$. Using the data obtained by carefully weighing the initial filter, dried filter, separated carbon, and mass increase of initial carbon, the ACT loaded per gram of carbon powder was obtained. In agreement with the absorbance readings, it was noted that small amounts of ACT were rinsed off the powder in washing with buffer. For Carbosieve S-III, differences in the absorbance results and the weight calculated results were observed. These differences were due to Carbosieve S-III's small pores adsorbing water, instead of ACT. Thus the weight calculated results showed that Carbosieve S-III retained water but did not adsorb any ACT.

For other powders the two methods (weight and absorbance measurements) were used simultaneously to calculate the amount of ACT per gram of carbon powder. In one set of experiments the amounts of ACT $(\mathrm{mg})$ per $\mathrm{g}$ of Carboxen carbon powder based on initial absorbance reading, based on absorbance reading excluding easily washed off ACT, and based on direct mass measurements of dried powder containing ACT for C-1012 were $622,609,601$; for $\mathrm{C}-1003$ were 406, 387, 400; for C-1000 were 366, 336, 356; and for C-1018 were 205, 198, and 198; respectively. To check the consistency of repeated loading experiments, four C-1012 samples $(0.0999,0.0996,0.0996,0.1000 \mathrm{~g})$ along with a control with carbon $(0.0999 \mathrm{~g})$ but no ACT and another control with ACT but no carbon was placed in $10 \mathrm{~mL}$ of 10 $\mathrm{mg} / \mathrm{mL}$ ACT in PBS for 72 hours at $25^{\circ} \mathrm{C}$. The results of absorbance based determinations after ACT loading amounts gave $605,579,573$, and $564 \mathrm{mg} / \mathrm{g}$ for average of 580.3 and a 17.6 standard deviation. The associated mass based determinations for the same four samples were $598,577,578$, and $565 \mathrm{mg} / \mathrm{g}$ with an average of 579.5 and a 13.7 standard deviation. Both the absorbance based and direct weightings are consistent with averages of $580 \mathrm{mg} / \mathrm{g} \mathrm{C}$-1012. Controls showed adsorption loading amounts of zero or close to zero.

\subsection{Releasing}

Tables 3-5 show the results of three releasing experiment for five carbons. The data show a cumulative release over time. Carbosieve S-III was tracked for the entire first release and as expected showed no ACT release since none had been adsorbed. Carbosieve S-III was not followed any further after the first release.

Table 3 shows the first cumulative release data which is plotted in Figure 1. The carbon powder was kept in the $250 \mathrm{~mL}$ of buffer solution at $\mathrm{pH}=7.0$ and $37^{\circ} \mathrm{C}$ for 96 hours. There was no shaking of samples in the releasing experiments. In the first two hours, the carbon released ACT rapidly and then slowly leveled out over the next twenty-two hours. The Carboxen powders released about one fourth to one third of the original ACT adsorbed.

Table 4 and Figure 2 show the second cumulative release, in which the carbon powder was removed from the initial solution which contained the released ACT and placed in fresh buffer solution. Note the maximum amount of release for the $\mathrm{C}-1012$ generated a final solution that was about $230 \mathrm{mg} / 250 \mathrm{~mL}$ or about $1 \mathrm{mg} / \mathrm{mL}$, and all other solutions were less, for the first release. In the second release the maximum concentration of final solution for C-1012 was about $38 \mathrm{mg} / 250 \mathrm{~mL}$ or about $0.15 \mathrm{mg} / \mathrm{mL}$. For 48 hours the carbon powders released a relatively consistent amount of ACT per hour and then leveled. The carbons remained in the second solution for 72 hours. The Carboxen powders released approximately $4 \%$ to $7 \%$ of the ACT that they originally adsorbed in this second release.

Table 5 shows the third cumulative release in which the release was restarted and the carbon powders stayed in solution for a total of 146 hours. The carbon powders kept releasing ACT for 26 to 57 hours and then the concentration remained steady. The Carboxen powders released an amount equivalent to only $1 \%$ to $2 \%$ of the original loaded ACT that they had adsorbed.

Cumulative release studies continued with the final amounts released checked at week intervals $(168 \mathrm{hr})$ or one time near end of time at a two week (336 hr) interval. These week interval release experiments continued for total time of $1826 \mathrm{hr}$ or almost 11 weeks or until no fur ther ACT released was observed from a specific carbon. The results are shown in Table 6. The amount of ACT released generally continued to decrease for each incremental release. One exception was the fourth and fifth 
Table 3. First cumulative time release into $250 \mathrm{~mL}$ of phosphate buffer solution at $37^{\circ} \mathrm{C}$.

\begin{tabular}{|c|c|c|c|c|c|c|}
\hline Time (hr) & $\begin{array}{c}\text { CB Released } \\
\text { ACT/Carbon }(\mathrm{mg} / \mathrm{g})\end{array}$ & $\begin{array}{c}\text { CS Released } \\
\text { ACT/Carbon }(\mathrm{mg} / \mathrm{g})\end{array}$ & $\begin{array}{c}\text { C-1000 } \\
\text { Released } \\
\text { ACT/Carbon }(\mathrm{mg} / \mathrm{g})\end{array}$ & $\begin{array}{c}\text { C-1003 Released } \\
\text { ACT/Carbon } \\
(\mathrm{mg} / \mathrm{g})\end{array}$ & $\begin{array}{l}\text { C-1018 Released } \\
\text { ACT/Carbon } \\
(\mathrm{mg} / \mathrm{g})\end{array}$ & $\begin{array}{c}\text { C-1012 Released } \\
\text { ACT/Carbon }(\mathrm{mg} / \mathrm{g})\end{array}$ \\
\hline 0 & 0 & 0 & 0 & 0 & 0 & 0 \\
\hline 1 & 9 & 0 & 74 & 71 & 25 & 103 \\
\hline 2 & 11 & 0 & 104 & 90 & 35 & 145 \\
\hline 3 & 12 & 0 & 106 & 100 & 39 & 172 \\
\hline 4 & 12 & 0 & 111 & 103 & 44 & 179 \\
\hline 5 & 13 & 0 & 114 & 108 & 47 & 198 \\
\hline 6 & 13 & 0 & 116 & 109 & 49 & 206 \\
\hline 24 & 14 & 0 & 133 & 128 & 56 & 229 \\
\hline 30 & 14 & 0 & 134 & 126 & 56 & 228 \\
\hline 48 & 15 & 0 & 132 & 126 & 55 & 226 \\
\hline 53 & 15 & 0 & 133 & 127 & 55 & 231 \\
\hline 96 & 14 & 0 & 121 & 120 & 52 & 209 \\
\hline
\end{tabular}

Table 4. Second cumulative time release into $250 \mathrm{~mL}$ of phosphate buffer solution at $37^{\circ} \mathrm{C}$.

\begin{tabular}{cccccc}
\hline Time (hr) & $\begin{array}{c}\text { CB Released } \\
\text { ACT/Carbon (mg/g) }\end{array}$ & $\begin{array}{c}\text { C-1000 Released } \\
\text { ACT/Carbon (mg/g) }\end{array}$ & $\begin{array}{c}\text { C-1003 Released } \\
\text { ACT/Carbon (mg/g) }\end{array}$ & $\begin{array}{c}\text { C-1018 Released } \\
\text { ACT/Carbon (mg/g) }\end{array}$ & $\begin{array}{c}\text { C-1012 Released } \\
\text { ACT/Carbon (mg/g) }\end{array}$ \\
\hline 0 & 0 & 0 & 0 & 0 & 0 \\
0.167 & 1 & 1 & 2 & 1 & 3 \\
1 & 1 & 5 & 5 & 2 & 11 \\
2 & 2 & 7 & 7 & 2 & 15 \\
3 & 2 & 9 & 9 & 3 & 18 \\
4 & 3 & 11 & 11 & 3 & 22 \\
6 & 3 & 14 & 14 & 7 & 34 \\
30 & 4 & 22 & 23 & 8 & 36 \\
48 & 4 & 23 & 24 & 10 & 38 \\
72 & 4 & 25 & 26 & 9 & 38 \\
\hline
\end{tabular}

Table 5. Third cumulative time release into $250 \mathrm{~mL}$ of phosphate buffer solution at $37^{\circ} \mathrm{C}$.

\begin{tabular}{cccccc}
\hline Time (hr) & $\begin{array}{c}\text { CB Released } \\
\text { ACT/Carbon (mg/g) }\end{array}$ & $\begin{array}{c}\text { C-1000 Released } \\
\text { ACT/Carbon (mg/g) }\end{array}$ & $\begin{array}{c}\text { C-1003 Released } \\
\text { ACT/Carbon (mg/g) }\end{array}$ & $\begin{array}{c}\text { C-1018 Released } \\
\text { ACT/Carbon (mg/g) }\end{array}$ & $\begin{array}{c}\text { C-1012 Released } \\
\text { ACT/Carbon (mg/g) }\end{array}$ \\
\hline 0 & 0 & 0 & 0 & 0 & 0 \\
1 & 0 & 1 & 1 & 0 & 2 \\
2 & 0 & 1 & 8 & 1 & 8 \\
26 & 1 & 6 & 9 & 2 & 10 \\
146 & 2 & 8 & 9 & 3 & 9 \\
\hline
\end{tabular}


Table 6. Incremental releases over extended time range with release into $250 \mathrm{~mL}$ of phosphate buffer solution at $37^{\circ} \mathrm{C}$.

\begin{tabular}{|c|c|c|c|c|c|c|c|}
\hline \multirow{2}{*}{$\begin{array}{l}\text { Incremental } \\
\text { Release }\end{array}$} & \multirow{2}{*}{ Time Interval (hr) } & \multirow{2}{*}{$\begin{array}{l}\text { Time Total } \\
\text { (hr) }\end{array}$} & \multicolumn{5}{|c|}{ Drug per Carbon released (mg/g) } \\
\hline & & & $\mathrm{CB}$ & C-1000 & C-1003 & C-1018 & C-1012 \\
\hline 1 & 96 & 96 & 14 & 121 & 120 & 52 & 209 \\
\hline 2 & 72 & 168 & 4 & 24 & 26 & 9 & 38 \\
\hline 3 & 146 & 314 & 2 & 7 & 9 & 3 & 9 \\
\hline $4^{*}$ & 168 & 482 & 0.3 & 2.3 & 2.8 & 0.7 & 3.1 \\
\hline 5 & 168 & 650 & 0.5 & 3.5 & 4.1 & 1.3 & 4.7 \\
\hline 6 & 168 & 818 & 0.3 & 2.7 & 3.1 & 1.1 & 3.1 \\
\hline 7 & 168 & 986 & 0.6 & 2.1 & 2.3 & 0.7 & 2.5 \\
\hline 8 & 168 & 1154 & 0 & 1.2 & 1.3 & 0.1 & 1.4 \\
\hline 9 & 168 & 1322 & 0 & 0.9 & 0.9 & 0 & 1.1 \\
\hline 10 & 336 & 1658 & 0 & 0.7 & 0.6 & 0 & 0.7 \\
\hline 11 & 168 & 1826 & 0 & 0.9 & 0.9 & 0 & 1.1 \\
\hline
\end{tabular}

${ }^{*}$ Bath temperature at $25^{\circ} \mathrm{C}$ for one week showed less release than subsequent week.

incremental releases. The carbon powders released less in the fourth release (the bath that was at $25^{\circ} \mathrm{C}$ during the week). This decrease in release during week four demonstrated the temperature effect in that the amount released that week was less than in subsequent week five. Another exception was near the end of the 11 week time period although the amounts are small and uncertainty greater by that time.

The amount of ACT loaded on each of the carbon powders has some correlation to the total amount of ACT released. For example, Carboxen 1012 loaded and released the most ACT and Carbopack B loaded and released the least amount of ACT. This comparison is true for all of the carbon powders. Consider the loading $(\mathrm{mg} / \mathrm{g})$ in Table 2 which is 622, 406, 366, and 205 for C-1012, C-1003, C-1000, and C-1018, respectively. Compare these results to the total cumulative release also expressed in units of mg of ACT per $\mathrm{g}$ of carbon of 274, 171, 167, and 67 for C-1012, C-1003, C-1000, and C-1018, respectively. Carboxen 1012 loaded the most and was able to release the most ACT over an 11 week period. C-1012, C-1003, and C-1000 each released about $44+/-2 \%$ of their loading capacity. C-1018 released about $33 \%$ of its loaded ACT which might be expected since it has the smallest pores of the Carboxen powders used.

Figure 3 combines all the cumulative releases of Carboxen 1012 over a period of eleven weeks. There is a period of rapid release followed by a longer period of slower steady release over many weeks. These results demonstrate how the release rate could be controlled by loading carbon, allowing for a rapid release, and then utilizing the carbon in a subsequent, applied slow-release mode which could continue for many weeks.

\section{Discussion}

Compared to other forces, such as covalent and ionic bonds, van der Waals interactions are relatively weak and yet these van der Waals interactions allow ACT to be attracted to the surfaces, crevices, and pores of the activated carbon. However, the BET surface area alone does not provide a good prediction of drug adsorption, but rather pore distribution must also be considered. Carbosieve S-III provides an extreme example of this observation in that although it had a BET area of $975 \mathrm{~m}^{2} / \mathrm{g}$ it adsorbed essentially no ACT. Relative to other powders used in this study the Carbosieve S-III is unique in having porosity present but having pores that are too small to accommodate the acetaminophen molecule.

In a prior study a slit pore edge separation of $(d=0.55$ $\mathrm{nm}$ ) was found for Carbosieves S-III [21]. Additionally it was observed that in a column packed with Carbosieve S-III smaller molecules including methane, ethane, propane, butane, 2-methylpropane, chloromethane, chlorodifluoromethane, and dichloromethane went slowly through the column because they could enter and interact with the pores in Carbosieve S-III. However, the larger molecules including sulfur hexafluoride, 2,2-dimethyl-propane, and 2,2-dimethylbutane went more rapidly through the gas chromatography column because they could not fit into the pores [21]. The space filling $\mathrm{x}, \mathrm{y}, \mathrm{z}$ measurements (MM2 molecular mechanics parameters) for water gave dimensions of $0.39,0.33$, and $0.30 \mathrm{~nm}$ and for acetaminophen with the amide group at a 90 degree angle to the benzene ring gave dimensions of $1.20,0.68$, and 0.61 $\mathrm{nm}$. With the acetaminophen in the more flat configuration the dimensions are $1.16,0.72$, and $0.40 \mathrm{~nm}$. 


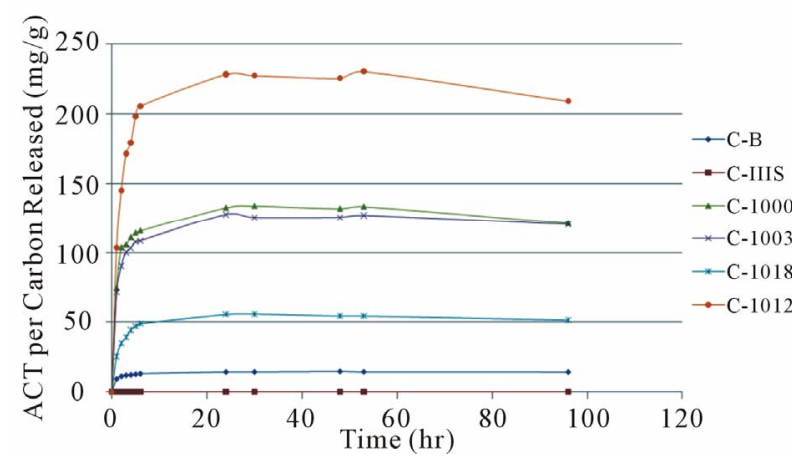

Figure 1. First cumulative time release. From top to bottom the powders are C-1012, C-1000, C-1003, C-1018, CB (C-B), and CS (C-IIIS).

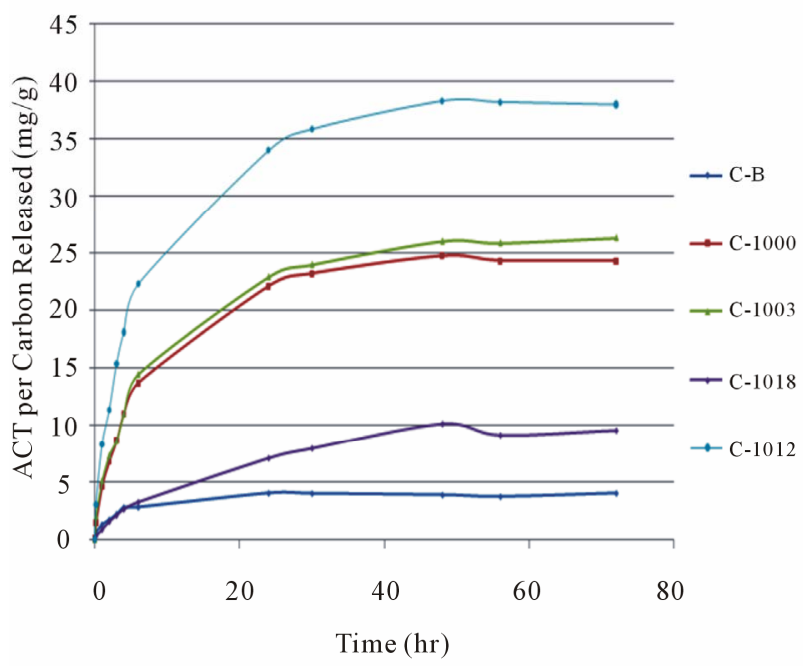

Figure 2. Second cumulative time release after 96 hours of first release. From top to bottom the powders are CB (C-B), C-1003, C-1000, C-1018, and C-1012.

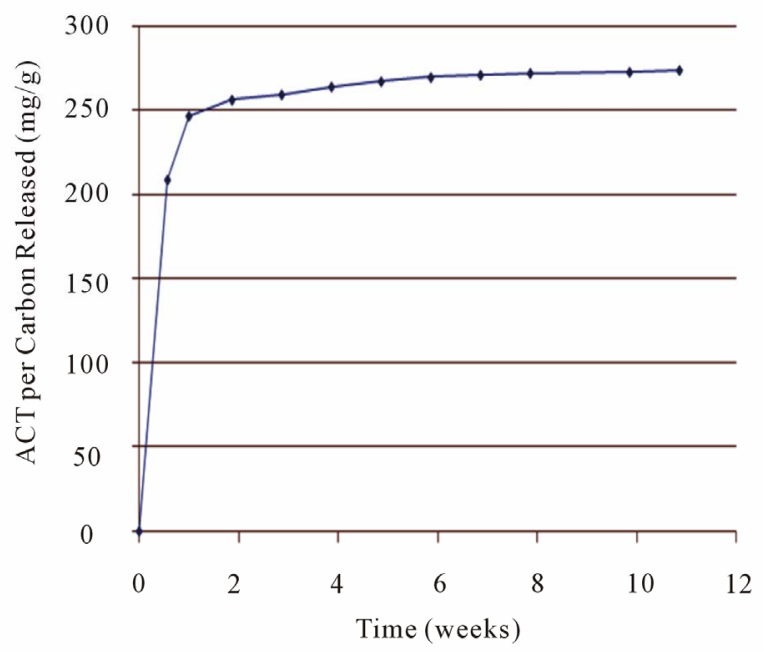

Figure 3. Combining all the cumulative releases of Carboxen 1012 over a period of eleven weeks.
It was observed that the degassing conditions were adequate to remove adsorbed water from all the solids except the microporous Carbosieve S-III and that is why there was a discrepancy between mass measurements and absorbance based measurements of ACT loading for this carbon powder. For the other powders the degassing was adequate and we wished to retain suitable but milder degasssing conditions. The smaller microporous material (Carbosieve S-III) was not suitable for drug loading despite a significant BET surface area. Also, as expected, powders with small BET areas (Carbopack B) provide little surface for drug loading. We also observed that having additional macroporosity (Carboxen-1000 and Carboxen-1003) did not enhance adsorption for a small molecule like ACT. Rather we found, as shown in the Equation (10) correlation, that mesoporosity dominates and adequate sized microporosity contributes to adsorption of a molecule like ACT. However, we would expect this trend to shift toward larger pores as the adsorbate molecule itself became larger.

Some advantages of using carbon powders as a drug delivery device have been shown. Carbon powders were attracted to lymph nodes and tumor surfaces near the injection site [8]. Some carbon powders release various drugs slowly over a period of time $[9,10]$. Unlike mesoporous silica, carbon powders have no charge on their surface and are a hydrophobic material, allowing them the potential to load and release proteins as well as remain structurally stable under aqueous conditions [17]. Thus there is general ongoing interest in new methods of drug storage and drug release, but there have been relative few studies of comparing carbon porosity to the amount retained and released. Liang Dong et al. did observed two carbon powders with different pore size ranges [18].

The adsorption method developed resulted in placing $0.1 \mathrm{~g}$ of carbon powders in $10 \mathrm{~mL}$ of ACT solution (10 $\mathrm{mg} \mathrm{ACT} / \mathrm{mL}$ in $\mathrm{pH}=7.0$ PBS) and then shaking them for 72 hours at $25^{\circ} \mathrm{C}$. The results show that carbon powders with mesopore volume size loaded more ACT. Carboxen 1012 with the maximum mesoporosity, $0.66 \mathrm{~cm}^{3} / \mathrm{g}$ volume of mesopores, adsorbed the most ACT. The amount adsorbed from the loading solution was reduced slightly by more extensive rinsing. When rinsing with about 40 $\mathrm{mL}$ buffer solution (4 times the amount originally used for loading) a small amount of ACT was removed leaving the loaded amount at about $580 \mathrm{mg} / \mathrm{g}$ or $58 \%$ ACT relative to original mass of carbon. Obviously, continued and extensive rinsing could gradually remove ACT from pores. After this rinsing and drying of the powders they visually appeared no different than prior carbons. However, the powder masses were larger and their pores contained loaded ACT that could be released into solution.

In repeated experiments, five samples of Carboxen 1012 loaded an average of $576+/-18 \mathrm{mg} / \mathrm{g}$ with a per- 
cent standard deviation error of $+/-3.1 \%$ ). In previous research, it was observed that Nuchar SA carbon powder loaded $323 \mathrm{mg} / \mathrm{g}$ of ACT [20]. In research by Liang Dong et al., they found that an activated carbon powder (pore size between 2 to $11 \mathrm{~nm}$ ) adsorbed $358 \mathrm{mg} / \mathrm{g}$ of ACT and released 7\% of its ACT in 12 hours. Also, they found that activated carbon with a wider pore size distribution adsorbed $281 \mathrm{mg} / \mathrm{g}$ of ACT and released $27 \%$ of its ACT in 12 hours. Most of the carbon powders used in this research released more ACT (comparing the percent the carbon powders adsorbed) in a shorter amount of time than in Liang Dong's research. However, our method of loading ACT placed more ACT into carbon than in prior studies.

Drug release profiles are essential in preventing harmful side-effects of a drug and achieving the therapeutic results of a drug [22]. Typically after an intial dose, drug concentration level rapidly rises, and then exponentially decays as the drug is metabolized and/or is eliminated from the body. Too high of a drug dosage can result in toxic side effects, and too low of a drug dosage can result in the drug concentration being too low to cause a therapeutic effect [22]. Thus it can be difficult to achieve the desired therapeutic range. Control release devices are advantageous to maintain a drug's desired blood plasma level for longer periods of time without reaching a toxic level or dropping below the minimum effective level [22].

Rudge et al. observed magnetically targeted carriers, MTCs, (a composite of metallic iron and activated carbon microparticles) loading and releasing various drugs (doxorubicin (DOX), mitomycin C, captothecin, methotrexate, and varapamil) [23]. The results revealed that the activated carbon adsorbed and desorbed each drug at different rates and concentrations. In addition, the releasing rate could be controlled by the amount of drug loaded onto the activated carbon.

Qinghe Zhao et al. studied the loading and releasing of the antitumor drug doxorubicin (DOX) in multilayered microcapsules (a carboylmethy cellulose was chemically altered to be negatively charged with a pore size range of 3 to $14 \mathrm{~nm}$ ) [24]. Before performing in vivo animal experiments and in vitro cell cultures, the releasing of DOX was observed in a solution of PBS (pH 7.4). After loading $132 \mathrm{mg} / \mathrm{mL}$ DOX concentration in the multilayered microcapsules, the release (desorption) rate of DOX from the delivery system was very rapid at first and then plateaued after 6 hours. We observed a similar effect.

The amount of ACT released over a period of time corresponds to the amount of ACT loaded on the various carbon powders (see Tables 2 and 6). The more ACT loaded onto the carbon powder, the more ACT was released from that carbon powder. Adsorbing and releasing the most, Carboxen 1012 (loaded with up to $622 \mathrm{mg} / \mathrm{g}$ ) in the first cumulative release released the equivalent of 209 mg of ACT per $g$ of carbon and most of this amount came in the first $6 \mathrm{hr}$. In a longer time scale the ACT loaded C-1012 was able to release ACT equivalent to a few to one $\mathrm{mg} / \mathrm{g}$ continuing for up to almost 11 weeks. The results show that different amounts of ACT can be released over a period of time depending on the carbon powder and/or the incremental release used. The amount of drug released can be regulated by the physical characteristics of the carbon powder and/or by the number of cumulative time releases. In future work, it would be of interest to explore other larger drug or drug analog molecules, and determine their loading and releasing characteristics for various carbonaceous materials.

\section{Conclusions}

Among investigations of various porous drug storage and release devices there has been limited systematic exploration of how the porosity and surface area affects the total storage and subsequent release of drug adsorbates. For this reason we studied carbon powders having a range of porosity including: Carboxen 1000 (C-1000), Carboxen 1003 (C-1003), Carboxen 1012 (C-1012), Carboxen 1018 (C-1018), Carbopack B (CB), and Carbosieve S-III (CS). Among these powders, the BET surface area varied from 90 to $1500 \mathrm{~m}^{2} / \mathrm{g}$ and total porosity varied from 0 to $0.85 \mathrm{~cm}^{3} / \mathrm{g}$.

Actaminophen (ACT) was chosen as a suitable small molecule drug analog to use for an adsorbate. Carbosieve S-III, with a surface area of $975 \mathrm{~m}^{2} / \mathrm{g}$, unlike the other carbons adsorbed no ACT from solutions of $10 \mathrm{mg} \mathrm{ACT/}$ $\mathrm{mL}$ in $\mathrm{pH}=7.0$ phosphate buffer solution at $25^{\circ} \mathrm{C}$ when exposed for 72 hours. CS has uniform micro pores of uniform small size that excludes the ACT molecules. The nonporous $\mathrm{CB}$ with a surface area of $90 \mathrm{~m}^{2} / \mathrm{g}$ adsorbed just $23 \mathrm{mg} / \mathrm{g}$ whereas at the mesoporous C-1012 with an area of $1500 \mathrm{~m}^{2} / \mathrm{g}$ loaded at most up to $622 \mathrm{mg} / \mathrm{g}$. A portion of the ACT removed from solution could be easily washed off the powder, but after washing in the above experiments 16 and $609 \mathrm{mg} / \mathrm{g}$ remained for the $\mathrm{CB}$ and C-1012, respectively - according to absorbance based measurements. The C-1012 carbon powder has a pore volume dominated by mesoporosity. And in repeated solution absorbance measurements was able to adsorb and retain after washing about $58 \%$ of its original mass in ACT. This maximum amount adsorbed for C-1012 was more than previously reported amounts of ACT adsorption for other carbons.

And for carbons like the C-1012, the amounts of ACT removed were large enough to be able to determine the amount adsorbed directly from mass increases. Repeated measurements for four samples of this carbon based on both mass changes and absorbance yielded a range of values from 564 to 605 with an average of ACT held in 
the powder of $580 \mathrm{mg} / \mathrm{g}$ of the original powder mass. Visually the loaded powder appeared no different with its pores filled with ACT molecules than when no ACT was adsorbed.

Multiple linear regression was carried with $\mathrm{V}_{\text {Micro }}=0$ for Carbosieve S-III whose pores were uniformly too small for adsorption of ACT with only micropore and mesopore volumes as variables and the results showed that microporosity contributes but the mesoporosity dominates the amount of ACT adsorbed.

The procedure consisted of loading the carbon powders in a concentrated solution of ACT, isolating the drug loaded carbon powders, and then releasing the ACT loaded on these carbon powders in a buffer solution at a $\mathrm{pH}$ of 7.0 and temperature of $37^{\circ} \mathrm{C}$. The release from the different carbons followed somewhat similar patterns based on an initially rapid but then much slower extended release with slow release continuing for even up 11 weeks of measurements.

The results suggest that it would be of interest to examine a larger set of powders of diverse porosity guided by the dominance of mesoporosity along with contributions of larger microposity. Mesoporous carbons may provide useful containers for holding and releasing a variety of therapeutic drug molecules.

\section{Acknowledgements}

This work was supported by the Grote Chemistry Fund at the University of Tennessee at Chattanooga.

\section{REFERENCES}

[1] B. Alberto, K. Kostas and P. Maurizio, "Applications of Carbon Nanotubes in Drug Delivery," Current Opinion in Chemical Biology, Vol. 9, No. 6, 2005, pp. 674-679. doi:10.1016/i.cbpa.2005.10.005

[2] N. Kam, M. O'Connell, J. Wisdom and H. Dai, "Carbon Nanotubes as Multifunctional Biological Transporters and Near-Infrared Agents for Selective Cancer Cell Destruction," Proceedings of the National Academy of Sciences, Vol. 102, No. 33, 2005, pp. 11600-11605. doi:10.1073/pnas.0502680102

[3] K. Cedric, K. Kostas, P. Maurizio and B. Alberto, "Functionalized Carbon Nanotubes as Emerging Nanovectors for the Delivery of Therapeutics," Biochimica et Biophysica Acta (BBA)-Biomembranes, Vol. 1785, No. 3, 2006, pp. 404-412. doi:10.1016/j.bbamem.2005.10.008

[4] P. Taylor, "Australian Nanotech Firm Eyes Drug Delivery Market," Decisionnewsmedia, 2004. http://www.in-pharmatechnologist.com/Materials-Formulat ion/Australian-nanotech-firm-eyes-drug-delivery-market

[5] P. Horcajada, A. Ramila, J. Perez-Pariente and M. Vallet-Regi, "Influence of Pore Size of MCM-41 Matrices on Drug Delivery Rate," Microporous and Mesoporous Materials. Vol. 68, No. 1-3, 2004, pp. 105-109. doi:10.1016/j.micromeso.2003.12.012

[6] Y. Zhu, J. Shi, W. Shen, X. Dong, J. Feng, M. Ruan and Y. Li, "Stimuli-Responsive Controlled Drug Release from a Hollow Mesoporous Silica Sphere/Polyelectrolyte Multilayer Core-Shell Structure," Angewandte Chemie International Edition, Vol. 44, No. 32, 2005, pp. 50835087. doi:10.1002/anie.200501500

[7] Y. Li, J. Shi, Z. Hua, H. Chen, M. Ruan and D. Yan, "Hollow Spheres of Mesoporous Aluminosilicate with a Three-Dimensional Pore Network and Extraordinarily High Hydrothermal Stability," Nano Letters, Vol. 3, No. 5, 2003, pp. 609-612. doi:10.1021/n1034134x

[8] A. Hagiwara, T. Takahashi, S. Kondoh, A. Iwamoto and K. Sawai, "Targeting Chemotherapy with Activated Carbon Particles Adsorbing Anticancer Drugs," Japanese Journal of Cancer \& Chemotherapy, Vol. 15, No. 4, 1988, pp. 1038-1042.

[9] A. Hagiwara, T. Takahashi, K. Kitamura, C. Sakakura, M. Shirasu, M. Ohgaki, T. Imanishi and J. Yamasaki, "Endoscopic Local Injection of a New Drug Delivery Formulation, Anticancer Drug Bound to Carbon Particles for Digestive Cancers-A Pilot Study," Journal of Gastroenterology, Vol. 32, No. 2, 1997, pp. 141-147. doi:10.1007/BF02936359

[10] C. Lu, L. Ling, S. Yuan, D. Liang and Y. Li, "Adsorption and Sustained-Release of Nifedipine in Spherical Activated Carbon," New Carbon Materials, Vol. 22, No. 1, 2007, pp. 17-22.

[11] T. Kim, P. Chung, I. Slowing, M. Tsunoda, E. Yeung and V. S. Lin, "Structurally Ordered Mesoporous Carbon Nanoparticles as Transmembrane Delivery Vehicle in Human Cancer Cell," Nano Letters, Vol. 8, No. 11, 2008, pp. 3724-3727. doi:10.1021/n1801976m

[12] S. Matsumoto, A. Iwamoto, C. Yoneyama, A. Hagiwara, T. Takahashi, H. Yoshikawa and S. Muranishi, "Adsorption and Desorption of Aclarubicin onto and from Activated Carbon Particles as Drug Carrier," Japanese Journal of Cancer \& Chemotherapy, Vol. 18, No. 2, 1991, pp. 227-231.

[13] C. Yoneyama, "Studies of Aclarubicin Adsorbed on Activated Carbon Particles for Clinical Application to Carcinomatous Peritonitis," Kyoto-Furitsu Ika Daigaku Zasshi, Vol. 101, No. 12, 1992, pp. 1097-108.

[14] Q. Qu, Y. Zhang and L. Sun, “Adsorption and Sustained Release of Mitomycin C by Activated Carbon Nano-Particles," Bulletin of the Academy of Military Medical Sciences, Vol. 28, No. 6, 2004, pp. 552-554, 561.

[15] Q. Qu, Y. Zhang and L. Sun, "Intraperitoneal Chemotherapy with Mitomycin C Bound to Activated Carbon Nanoparticles for Nude Mice Bearing Human Gastric Carcinoma," Chinese Journal of Oncology, Vol. 28, No. 4, 2006, pp. 257-260.

[16] N. Hoshino, N. Shibata, T. Minouchi, H. Shimakawa and A. Yamaji, "Preparation of Controlled-Release System Using Activated Charcoal and Its Application to Enema," Japanese Journal of Hospital Pharmacy, Vol. 19, No. 6, 1993, pp. 509-515.

[17] A. Vinu, M. Miyahara and K. Ariga, "Assemblies of 
Biomaterials in Mesoporous Media," Journal of Nanoscience and Nanotechnology, Vol. 6, No. 6, 2006, pp. 1510-1532. doi:10.1166/jnn.2006.253

[18] D. Liang, C. Lu, Y.-L. Li and Y.-H. Li, “Adsorption of Paracetamol by Activated Carbon and Its Release in Vitro," New Carbon Materials, Vol. 21, No. 2, 2006, pp. 144-150.

[19] T. Lee, C. S. Kuo and Y. H. Chen, "Solubility, Polymorphism, Crystallinity, and Crystal Habit of Acetaminophen and Ibuprofen by Initial Solvent Screening," 2006.

http://pharmtech.findpharma.com/pharmtech/Active+ingr edents/Solubility-Polymorphism-Crystallinity-and-Crysta 1-/ArticleStandard/Article/detail/378746

[20] T. R. Rybolt, D. E. Burrell, J. M. Shults and A. K. Kelley, "In Vitro Coadsorption of Acetaminophen and N-Acetylcysteine onto Activated Carbon Powder," Journal of Pharmaceutical Sciences, Vol. 75, No. 9, 1986, pp. 904906. doi:10.1002/jps.2600750918

[21] T. R. Rybolt, K. Ziegler, H. E. Thomas and J. L. Boyd, "Adsorption Energies for a Nanoporous Carbon from
Gas-Solid Chromatography and Molecular Mechanics," Journal of Colloid and Interface Science, Vol. 296, No. 1, 2006, pp. 41-50. doi:10.1016/j.jcis.2005.08.057

[22] B. D. Ratner, A. S. Hoffman, F. J. Schoen and J. Lemons, "Biomaterials Science: Introduction to Material in Medicine," 2nd Edition, Elsevier Academic Press, New York, 2004, pp. 628-645.

[23] S. Rudg, C. Peterson, C. Vessely, J. Koda, S. Stevens and L. Catterall, "Adsorption and Desorption of Chemotherapeutic Drugs from a Magnetically Targeted Carrier (MTC)," Journal of Controlled Release, Vol. 74, No. 1-3, 2001, pp. 335-340. doi:10.1016/S0168-3659(01)00344-3

[24] Q. Zhao, B. Han, Z. Wang, C. Gao, C. Peng and J. Shen, "Hollow Chitosan-Alginate Multilayer Microcapsules as Drug Delivery Vehicle: Doxorubicin Loading and in Vitro and in Vivo Studies," Nanomedicine: Nanotechnology, Biology and Medicine, Vol. 3, No. 1, 2007, pp. 63-74. doi:10.1016/j.nano.2006.11.007 